See discussions, stats, and author profiles for this publication at: https://www.researchgate.net/publication/320400865

\title{
Phase evolution of EBPVD coated ceria-zirconia nanostructure and its impact on high temperature oxidation of AISI 304
}

Article in Corrosion Science · October 2017

DOI: 10.1016/j.corsci.2017.09.026

\section{CITATIONS}

4

5 authors, including:

Aadhavan Ramanathan

6 PUBLICATIONS 19 CITATIONS

SEE PROFILE

Suresh Babu Krishna Moorthy

Pondicherry University

74 PUBLICATIONS 1,249 CITATIONS

SEE PROFILE

Some of the authors of this publication are also working on these related projects:

Evaluation of CD147 as a potential target for cancer therapy View project

Project Ionic and Protonic conducting electrolytes for solid oxide fuel cell View project
- Parthasarathi Bera

National Aerospace Laboratories 131 PUBLICATIONS 3,897 CITATIONS SEE PROFILE 


\title{
Phase evolution of EBPVD coated ceria-zirconia nanostructure and its impact on high temperature oxidation of AISI 304
}

\author{
R. Aadhavan ${ }^{\mathrm{a}}$, Parthasarathi Bera ${ }^{\mathrm{b}}$, C. Anandan ${ }^{\mathrm{b}}, \mathrm{S}$. Kannan ${ }^{\mathrm{a}}$, K. Suresh Babu ${ }^{\mathrm{a}, *}$

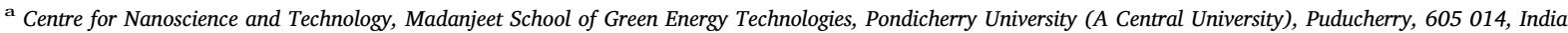 \\ b Surface Engineering Division, CSIR - National Aerospace Laboratories, Bengaluru 560017, India
}

\section{A R T I C L E I N F O}

\section{Keywords:}

EBPVD

Nanostructures

High Temperature Oxidation

Thin Films

Cera-Zirconia

\begin{abstract}
A B S T R A C T
The present work focusses on the effect of nanocrystalline $\mathrm{xCeO} 2-(1-\mathrm{x}) \mathrm{ZrO} 2(\mathrm{x}=1,0.75,0.5,0.25$ and 0 in wt $\%$ abbreviated as C100, C75Z25, C50Z50, C25Z75 and Z100) coated by electron beam physical vapour deposition (EBPVD) on AISI 304 and its implication on the high-temperature oxidation protection. The oxidation kinetics indicate that the samples C100, C75Z25 and C50Z50 show 3-4 orders better oxidation protection than uncoated AISI 304. Coating morphology and composition play an important role in developing superior nanostructures against high temperature oxidation. The development of ceria-zirconia coating helps in the realization of structural materials for elevated temperature application.
\end{abstract}

\section{Introduction}

Austenitic stainless steels are used as structural materials at elevated temperature oxidation. In particular, AISI 304 has been in power plants, petroleum refineries and fast breeder reactors [1-3]. At higher temperatures, these materials are subjected to oxidation that leads to degradation of the material and its lifetime is significantly reduced. On oxidation, AISI 304 develops protective chromia layer on the surface but fails above $870{ }^{\circ} \mathrm{C}$ due to the thermal expansion coefficient mismatch caused by thermal stress and the formation of iron oxides, iron chromate $\left(\mathrm{Fe}_{2} \mathrm{Cr}_{2} \mathrm{O}_{4}\right)$ and manganese chromate $\left(\mathrm{Mn}_{1.5} \mathrm{Cr}_{1.5} \mathrm{O}_{4}\right)$ through the initially formed chromia layer $[3,4]$.

Ceria based materials are the potential candidate in the field of high-temperature oxidation protection [1]. The success of ceria-based materials is mainly ascribed to the unique combination of high oxygen diffusivity coupled with the ability to shift easily between reduced $\mathrm{Ce}^{3+}$ and oxidized $\mathrm{Ce}^{4+}[5]$. The formation of oxygen vacancy in ceria can be represented using Kröger-Vink equation.

$2 \mathrm{Ce}_{\mathrm{Ce}}+\mathrm{O}_{\mathrm{O}} \rightarrow \frac{1}{2} \mathrm{O}_{2}+\mathrm{V}_{\mathrm{O}}^{\ddot{2}}+2 \mathrm{Ce}_{\mathrm{Ce}}^{\prime}$

where $\mathrm{Ce}_{C e}$ denotes $\mathrm{Ce}^{4+}$ in cerium lattice, $O_{o}$ represents oxygen in oxygen lattice, $V_{O}^{*}$ indicates oxygen vacancy and $C e_{C e}^{\prime}$ signifies $\mathrm{Ce}^{3+}$ in cerium lattice.

Ceria or cerium is successfully incorporated using alloying, oxide particle dispersion, ion implantation and surface coating [6,7]. Cerium in the alloying process and oxide particle dispersion changes the alloy properties as well as its processing such as hot working [8]. In abovementioned methods, the surface coating is reported as simple, economical and it does not affect its underlying alloy properties. Micron sized ceria coating using dip coating reportedly renders protection of stainless steels such as AISI 304, 316 and 321 against oxidation at $1423 \mathrm{~K}$ by changing in the diffusion process from outward cation to the inward anion [1]. But micron-sized ceria has been found to be less protective than its nano-sized counterpart [9]. Microceria and nanoceria coated by sol-gel/micro emulsion technique influencing the oxidation protection of AISI 304 at $1260 \mathrm{~K}$ have been matched and reported that the effectiveness of nanoceria is better in inhibiting oxidation [8]. It has been proved that particle size and the role of oxygen vacancy in nanoceria play substantial effect in oxidation protection. Thus, the nanostructures with higher oxygen vacancy concentration are shown to have the profound influence in high-temperature oxidation protection $[8,9]$. The presence of $30-40 \%$ oxygen vacancy in $\mathrm{CeO}_{2}$ is shown to be beneficial for the protection of alloy thereby showing 3-4 orders of reduction in mass gain. The role of $\mathrm{Ce}^{3+}$ or oxygen vacancy concentration in nanostructured ceria has been envisaged to provide an additional effect on improving high-temperature oxidation protection [10]. Despite the positive influence of nanoceria on the high-temperature oxidation protection of AISI 304, nanoceria coating using surface coating techniques such as dip coating, thermal spraying, modified CVD and electron beam physical vapour deposition (EBPVD) also play a significant role in the oxidation protection $[10,11]$. B. Bouchaud et al. (2014) reported that ceria films coated by electrodeposition method enhance the oxidation resistance by decreasing

\footnotetext{
* Corresponding author.

E-mail addresses: partho@nal.res.in (P. Bera), sureshbabu.nst@pondiuni.edu.in (S.B. K.).
} 
oxygen partial pressure at the substrate/ceria interface [12,13]. Dip coating and thermal spraying have inherent defects such as porosity and non-uniformity in the coating and it is difficult to control the thickness. Hence, it results in the formation of the iron-rich local regime during oxidation [14]. But EBPVD is reported as one of the best technique due to the control of the coating thickness at nanometer level and renders uniform and dense coating [15]. Aadhavan et al. reported that thickness of nanoceria coatings using EBPVD plays a crucial role in oxidation protection. The thickness at micrometer level provides better oxidation protection by the selective formation of chromia at steel/ nanoceria interface due to lower oxygen partial pressure at the steel/ nanoceria interface. Thaneeru et al. and Aadhavan et al. have reported the impact of lanthanum doped nanoceria on high-temperature oxidation protection of AISI $304[10,15]$. Aadhavan et al. have demonstrated that 5 at.\% lanthanum doped ceria renders better oxidation protection than nanoceria because of the availability of more oxygen vacancy. But increased dopant percentage of lanthanum in ceria results in higher mass gain during oxidation [16].

The choice of dopant species and its concentration in ceria-based materials are key factors in the high-temperature oxidation protection $[17,18]$. Zirconium with +4 oxidation state is widely used as either dopant or composite material for ceria. Unlike ceria, ceria and zirconia $\left(\mathrm{Ce}_{\mathrm{x}} \mathrm{Zr}_{1-\mathrm{x}} \mathrm{O}_{2}\right)$ can form the solid solutions in the certain composition range and existence of the three different phases observed namely monoclinic, tetragonal and cubic [19-22]. The addition of zirconium in the ceria increases the oxygen storage capacity due to the formation of oxygen vacancies. These vacancies act as an oxygen transport medium in fuel cells and catalysis. Owing to the high-temperature structural stability and the presence of oxygen vacancy of ceria-zirconia, it can also be used for the high-temperature oxidation protection. Oxygen vacancy in ceria-based materials is essential to control the transport of oxygen in ceria coated steels where protective chromia is formed [23]. In our present work, zirconium-doped ceria and ceria-zirconia mixed oxides have been coated using EBPVD. The change in structural parameters of as-coated samples is discussed in detail using X-ray diffraction and Raman spectroscopy. We are the first to report the effect of EBPVD coated zirconium-doped ceria and ceria-zirconia samples on the hightemperature oxidation protection of AISI 304.

\section{Materials and methods}

Nanocrystalline $\mathrm{xCeO}_{2}-(1-\mathrm{x}) \mathrm{ZrO}_{2}(\mathrm{x}=1,0.75,0.5,0.25$ and 0 , in wt.\%) composites were synthesized by chemical co-precipitation method. Cerium nitrate hexahydrate $\left(\mathrm{Ce}\left(\mathrm{NO}_{3}\right)_{3} \cdot 6 \mathrm{H}_{2} \mathrm{O}\right.$, Himedia, purity $\geq 99.9 \%$ ), zirconium nitrate oxyhydrate $\left(\mathrm{Zr}\left(\mathrm{NO}_{3}\right)_{3} \cdot 6 \mathrm{H}_{2} \mathrm{O}\right.$, Himedia, purity $\geq 99.9 \%$ ) were used as precursors for cerium and zirconium, respectively while $25 \%$ ammonia $\left(\mathrm{NH}_{3}\right.$, Himedia, analytical grade) was used as a precipitating agent. To a mixture containing the desired weight ratio of cerium and zirconium nitrate in double distilled water, ammonium hydroxide solution was added dropwise. The $\mathrm{pH}$ was maintained at 10 during the synthesis and stirred for about $5 \mathrm{~h}$ and the resultant precipitate was washed with deionised water, dried at $353 \mathrm{~K}$ for $8 \mathrm{~h}$. Various $\mathrm{xCeO}_{2}-(1-\mathrm{x}) \mathrm{ZrO}_{2}$ samples synthesized by precipitation method are coded as C100, C75Z25, C50Z50, C25Z75 and Z100 based on the weight fraction as given in Table 1. As-synthesized powders were consolidated into a green compact using a hydraulic press by applying the pressure of about 2.5 ton for $30 \mathrm{~s}$. The green pellet was subsequently annealed at $1473 \mathrm{~K}$ under the stagnant atmospheric condition for a dwelling time of $5 \mathrm{~h}$ and used as the target for thin film deposition.

The chemical composition (in weight percentage) of the AISI 304 stainless steel substrate used in the study was C, 0.08; Cr, 18.35; Mn, 1.84; Ni, 8.54; P, 0.045; S, 0.030; Si, 1.00; and the balance being Fe. AISI 304 coupons of dimensions $15 \mathrm{~mm} \times 15 \mathrm{~mm} \times 3 \mathrm{~mm}$ were polished using 600, 800, 1000 and 1200 grit SiC paper and subsequently cleaned with isopropyl alcohol in an ultrasonicator and then air dried.
The coupons were coated using EBPVD technique (Hind High Vacuum, Bengaluru, Model BC -300 ) at a base pressure of $3.75 \times 10^{-6}$ mbar. The voltage, substrate temperature and deposition rate of the coating were kept constant at $5 \mathrm{keV}, 373 \mathrm{~K}$ and $0.2 \AA^{-1}$, respectively for all the samples. While depositing, the thickness of the film was monitored by in situ digital thickness monitor (DTM) and then confirmed using a profilometer (Dektak 6, Veeco, USA). A coating thickness of $2 \mu \mathrm{m}$ was maintained in all the samples based on our earlier report [15].

The oxidation study was carried out in a custom-made computer controlled set up to monitor the real-time mass change of the samples at a constant temperature. Isothermal oxidation test was carried out on the bare as well as $\mathrm{xCeO}_{2}-(1-\mathrm{x}) \mathrm{ZrO}_{2}$ coated samples in normal atmospheric conditions at $1243 \mathrm{~K}$ for $24 \mathrm{~h}$. A balance (Shimadzu, Model AUW220D), having an accuracy of $\geq 0.01 \mathrm{mg}$ was used to measure the mass gain of the samples during the oxidation in real time using a computer controlled interface connected with the balance. For comparison, a bare AISI 304 coupon was tested under similar experimental conditions.

The crystalline phases were investigated using Rigaku Ultima IV Xray diffractometer (XRD) by employing $\mathrm{Cu} \quad \mathrm{K}_{\alpha}$ radiation $(\lambda=0.15418 \mathrm{~nm})$ with a scan rate of $0.06^{\circ} \mathrm{s}^{-1}$. Quantitative phase analyses through Rietveld refinement for the sintered targets were evaluated using GSAS-EXPGUI software package. The morphology of the oxide scale was studied using field emission scanning electron microscopy (FESEM, Carl Zeiss, Ultra 55). The elemental analysis was carried out using energy dispersive X-ray (EDX) system by Oxford XMax EDX detector attached with FESEM. In order to quantify the oxygen vacancy concentration, Raman spectroscopic studies were performed with Renishaw micro Raman spectrometer using a laser excitation wavelength of $514 \mathrm{~nm}$ with a power of $3 \mathrm{~mW}$. XPS of oxidized C100, C75Z25 and C50Z50 samples were recorded with a Specs spectrometer using $\mathrm{Al} K_{\alpha}(1486.6 \mathrm{eV})$ as the X-ray source. The binding energies were referenced with a C1 s peak at $284.6 \mathrm{eV}$. The Ce $3 \mathrm{~d}$ peaks were deconvoluted using PeakFit software (version 4.12).

\section{Results and discussion}

\subsection{Structural characterization of powder}

The XRD patterns of the as-synthesized powders are shown in Fig. 1(A). In general, ceria has cubic fluorite structure until its melting point while zirconia exists in monoclinic, tetragonal and cubic phases. Among the three phases of zirconia, the monoclinic structure is stable up to $1443 \mathrm{~K}$ while tetragonal (1443-2643 K) and cubic ( $>2643 \mathrm{~K}$ ) are stable at higher temperatures [24]. From Fig. 1(A), it can be seen that the as-synthesized C100 and C75Z25 crystallizes in cubic fluorite ceria structure matching with the standard ICDD data (01-081-0792). The absence of any other phase, except ceria in C75Z25, indicates the doping of $\mathrm{Zr}^{4+}$ in ceria lattice. With the increase in $\mathrm{ZrO}_{2}$ content, the peaks become broader with overlapping of peaks between (111) and (200). The as-synthesized C50Z50, C25Z75 powders show only cubic ceria phase while $\mathrm{ZrO}_{2}$ may be present in the amorphous form $[19,25]$. Zirconia without any cerium addition (Z100) exhibits a completely amorphous nature. The mean crystallite size (D) was calculated using Scherrer's formula given as follows

$D=\frac{0.91 \lambda}{\beta \cos \theta}$

where $\lambda, \theta$ and $\beta$ are the wavelength of X-ray, Bragg's angle and full width at half maxima of the peak, respectively. The calculated mean crystallite sizes are given in Table 1 which indicates a reduction in size with the increase in zirconium content. The as-synthesized ceria (C100) exhibits a size of $9 \mathrm{~nm}$ that becomes 7.1, 3.2 and $2.5 \mathrm{~nm}$ for C75Z25, C50Z50 and C25Z75, respectively. The presence of zirconium on the surface of the ceria nuclei inhibits the kinetics of growth of nanoparticles thereby reducing the crystallite size [26]. Lattice parameter 
Table 1

Mean crystallite size, lattice constant calculated from XRD spectra.

\begin{tabular}{|c|c|c|c|c|c|}
\hline \multirow[t]{2}{*}{ Sample Code } & \multirow[t]{2}{*}{ Chemical composition (in wt\%) } & \multicolumn{2}{|c|}{ Mean crystallite size ${ }^{a}(\mathrm{~nm})$} & \multicolumn{2}{|c|}{ Lattice constant (in nm) } \\
\hline & & Powder & Target & Powder & Target \\
\hline C100 & $100 \% \mathrm{CeO}_{2}$ & 9 & 84.1 & $0.5446^{\mathrm{a}}$ & $0.5412^{\mathrm{a}}$ \\
\hline C75Z25 & $75 \% \mathrm{CeO}_{2}-25 \% \mathrm{ZrO}_{2}$ & 7.1 & 82.7 & $0.5412^{\mathrm{a}}$ & $0.5409^{\mathrm{a}}$ \\
\hline C50Z50 & $50 \% \mathrm{CeO}_{2}-50 \% \mathrm{ZrO}_{2}$ & 3.2 & 42.4 & $0.5391^{\mathrm{a}}$ & $\begin{array}{l}0.5375^{\mathrm{a}} \\
0.3637(\mathrm{a})^{\mathrm{b}} \\
0.3637(\mathrm{~b})^{\mathrm{b}} \\
0.5241(\mathrm{c})^{\mathrm{b}}\end{array}$ \\
\hline C25Z75 & $25 \% \mathrm{CeO}_{2}-75 \% \mathrm{ZrO}_{2}$ & 2.5 & 39 & $0.5367^{\mathrm{a}}$ & $\begin{array}{l}0.5364^{\mathrm{a}} \\
0.3630(\mathrm{a})^{\mathrm{b}} \\
0.3630(\mathrm{~b})^{\mathrm{b}} \\
0.5221(\mathrm{c})^{\mathrm{b}}\end{array}$ \\
\hline $\mathrm{Z} 100$ & $100 \% \mathrm{ZrO}_{2}$ & - & 62.7 & - & $\begin{array}{l}0.5144(a)^{b} \\
0.5199(b)^{b} \\
0.5314(c)^{b}\end{array}$ \\
\hline
\end{tabular}

a Calculated parameters from $\mathrm{CeO}_{2}$.

b Calculated parameters from $\mathrm{ZrO}_{2}$.

for bulk ceria has been reported to be 0.5410 [27]. In comparison to bulk ceria, the lattice constant of the as-synthesized nanoceria (C100) was found to be larger $(0.5446 \mathrm{~nm})$ due to the presence of higher concentration of $\mathrm{Ce}^{3+}$ than $\mathrm{Ce}^{4+}$ (ionic radii of $\mathrm{Ce}^{3+}$ and $\mathrm{Ce}^{4+}$ are $0.1143 \mathrm{~nm}$ and $0.97 \mathrm{~nm}$, respectively). A reduction in crystallite size of ceria generally increases the lattice parameter due to the presence of a larger fraction of $\mathrm{Ce}^{3+}$ [5]. In spite of the lower crystallite size, the calculated lattice constant value for C75Z25 and C50Z50 has been found to be equal or smaller than that of bulk as well as nanoceria (C100). The reduction in lattice parameter can be attributed to the fact that the substitution of $\mathrm{Ce}^{4+}$ ions by smaller sized $\mathrm{Zr}^{4+}$ ions (ionic radius: $0.84 \mathrm{~nm}$ ) leads to a lattice contraction and a corresponding linear decrease in lattice constant with respect to zirconium content [28].

Raman scattering provides a valuable insight on the local structural changes with respect to zirconium addition. For bulk ceria, Raman peak appears at $465 \mathrm{~cm}^{-1}$ which is attributed to the symmetric $\mathrm{F}_{2 \mathrm{~g}}$ breathing mode of oxygen ions surrounded by the eight cerium ions in the cubic fluorite lattice. Fig. 1(B) shows the Raman spectra recorded for powders. Intense $F_{2 g}$ peak was observed at $463,465,466$ and $474 \mathrm{~cm}^{-1}$ for C100, C75Z25, C50Z50 and C25Z75, respectively. All the peaks are found to be broader and asymmetric in nature. It is due to the inhomogeneous strain broadening associated with dispersion in crystallite size and reduction of phonon lifetime in the nanocrystalline regime. The presence of Raman peak for $\mathrm{C} 100$ indicates the presence of crystalline ceria. The shift towards lower wave number than the bulk value for $\mathrm{C} 100$ arises due to the reduced crystallite size and the presence of defects (Tables 1 and 2). The observed blue shift towards higher wave number for C75Z25, C50Z50 and C25Z75 with the increase in $\mathrm{Zr}$ concentration can be attributed to the incorporation of smaller $\mathrm{Zr}^{4+}$ into the ceria lattice. The difference in ionic radii between $\mathrm{Ce}^{4+}$ and $\mathrm{Zr}^{4+}$ ion leads to the contraction of ceria lattice, as observed in XRD patterns which results in an asymmetric, more rapid vibration of the oxygen-cation-oxygen bond leading to shifting of the band to higher wave number. The blue shift typifies the strengthening of bonds which is consistent with a decrease in the lattice parameters. Unlike symmetric and sharper $\mathrm{F}_{2 \mathrm{~g}}$ band observed in other samples, C25Z75 exhibits multiple broader peaks. The $\mathrm{F}_{2 \mathrm{~g}}$ band in C25Z75 may overlap with that of tetragonal phase of $\mathrm{ZrO}_{2}$. In addition, an extended peak observed around $536 \mathrm{~cm}^{-1}$ which arise from the presence of tetragonal zirconia. Also, a distinct overlapping band is observed in the range of $610-660 \mathrm{~cm}^{-1}$ with the intensity maxima of around 626 and $650 \mathrm{~cm}^{-1}$. Zhang et al. (2006) have observed a similar overlapping of the above peaks which is attributed to the tetragonal phase of zirconia
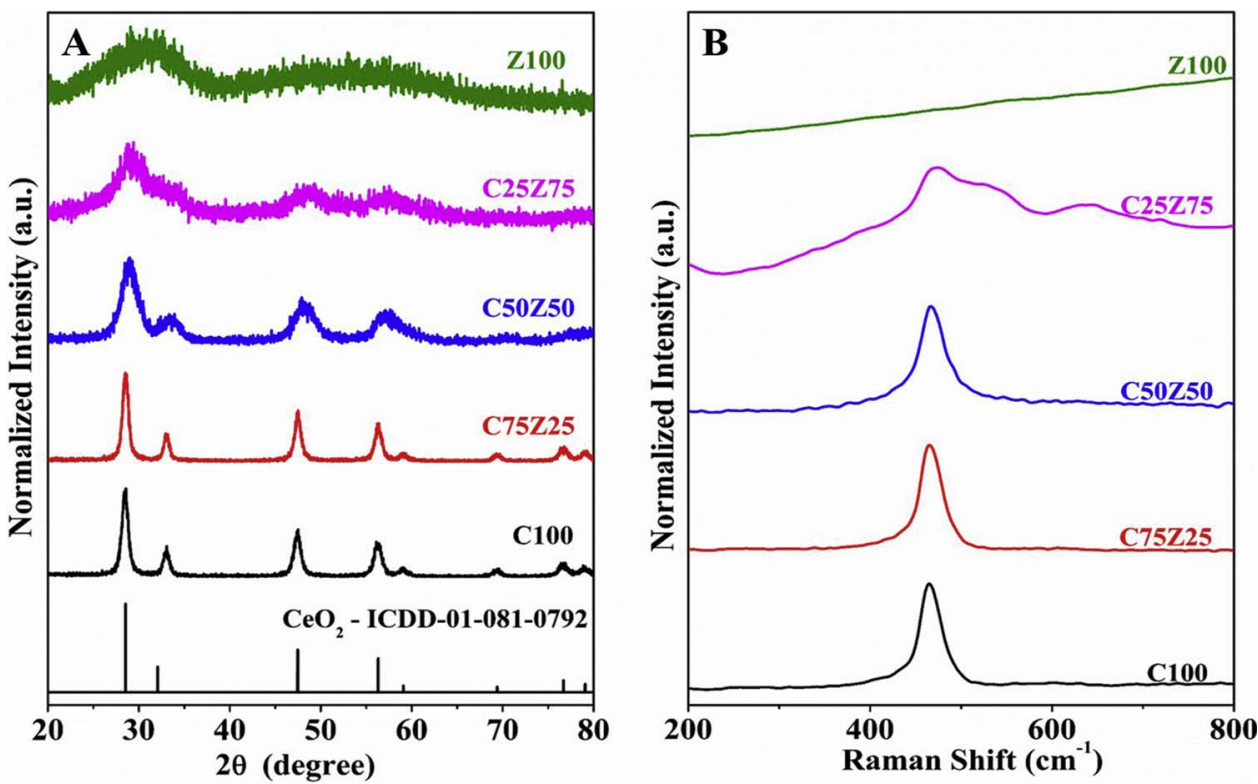

Fig. 1. XRD (A) and Raman (B) spectra of the as synthesized $\mathrm{xCeO}_{2}-(1-\mathrm{x}) \mathrm{ZrO}_{2}$. 
Table 2

Calculated oxygen vacancy defect concentration using Raman spectra.

\begin{tabular}{lllll}
\hline \multirow{2}{*}{ Sample } & \multicolumn{3}{l}{ Defect concentration $\left(\times 10^{21} \mathrm{~cm}^{-3}\right)$} & \\
\cline { 2 - 5 } & Powder & Target & As coated & After oxidation \\
\hline C100 & 1.6 & 0.63 & 2.1 & 1.2 \\
C75Z25 & 1.7 & 0.68 & 2.3 & 1.5 \\
C50Z50 & 2.3 & 1.4 & 3.1 & 2.2 \\
C25Z75 & 2.5 & 1.9 & - & 2.1 \\
Z100 & - & - & - & - \\
\hline
\end{tabular}

${ }^{\text {a }}$ Calculated from $\mathrm{F}_{2 \mathrm{~g}}$ band of $\mathrm{CeO}_{2}$.

$[25,29]$. Though cannot be identified in XRD, the presence of features at 536, 626 and $650 \mathrm{~cm}^{-1}$ which are noticeably absent in the other samples demonstrates the formation of tetragonal $\mathrm{ZrO}_{2}$ phase in C25Z75. The Raman peak observed around $606 \mathrm{~cm}^{-1}$ for the samples C100, C75Z25 and C50Z50 can be attributed to the presence of oxygen vacancy [13].

The oxygen vacancy present in the sample can be quantified using spatial correlation model [30]. From the $F_{2 g}$ band of ceria, oxygen vacancy concentration $(N)$ is calculated from the equation given below

$N=\frac{3}{4 \pi L^{3}}$

where $L$ is the correlation length that corresponds to the mean distance between two adjacent oxygen vacancies. Further,

$L=\sqrt[3]{\left(\frac{\alpha^{2}}{2 d_{g}}\right)^{2}\left[\left(d_{g}-2 \alpha\right)^{3}+4 d_{g}^{2} \alpha\right]}$

where $d_{g}$ and $\alpha$ is the grain size and radius of $\mathrm{CeO}_{2}$, respectively. The defect concentration calculated for the powders is shown in Table 2. With the increase in $\mathrm{Zr}^{4+}$ concentration the defect concentration increases from $1.6 \times 10^{21} \mathrm{~cm}^{-3}$ (C100) to $1.7-2.5 \times 10^{21} \mathrm{~cm}^{-3}$ (C25Z75) for the as synthesized powder. Yang et al. using density functional theory (DFT) calculation have shown that vacancy formation energy of pure $\mathrm{CeO}_{2}$ as $2.87 \mathrm{eV}$ while it lowers by $0.10 \mathrm{eV}$ for the $\mathrm{Ce}_{0.75} \mathrm{Zr}_{0.25} \mathrm{O}_{2}$ system [31]. Further, the creation of oxygen vacancy near to $\mathrm{Zr}^{4+}$ lowers the vacancy formation energy by $0.52 \mathrm{eV}$. Balducci et al. have calculated the energetics of $\mathrm{Ce}^{4+}$ to $\mathrm{Ce}^{3+}$ conversion and accredited the drop in the reduction energy to $\mathrm{Zr}^{4+}$ concentration in $\mathrm{CeO}_{2}-\mathrm{ZrO}_{2}$ solid solution [32]. The above discussions clearly demonstrate that with $\mathrm{Zr}^{4+}$ concentration (i) oxygen vacancy formation becomes easier and (ii) energetics favours the transformation of $\mathrm{Ce}^{4+}$ to $\mathrm{Ce}^{3+}$, thereby, enhancing the overall defect concentration (Table 2).

\subsection{Structural characterization of the target}

To understand the structural and phase changes upon sintering, XRD and Raman spectroscopic studies have been carried out. Unlike the as-synthesized samples, targets exhibit sharper peaks due to the temperature assisted crystal growth and structural transformation (Fig. 2A). For $\mathrm{C} 100$ and $\mathrm{C} 75 \mathrm{Z} 25$, only the cubic fluorite ceria phase $\left(c-\mathrm{CeO}_{2}\right)$ is observed while C50Z50 and C25Z75 exhibit both cubic ceria and tetragonal zirconia ( $t$-ZrO2) phases. In C50Z50, cubic phase of ceria is found to be predominant with respect to intensity than the tetragonal phase (ICDD- 01-070-7359) while in C25Z75 the reverse behaviour is observed. This phase separation or phase demixing arises from the surface energy of mixed $\mathrm{xCeO}_{2}-(1-\mathrm{x}) \mathrm{ZrO}_{2}$ [20]. The solid solution has been found to be stable when the crystallite size does not exceed a critical size. Above the critical size of crystallites, the surface energy contribution to the total energy of the crystal system is too low to stabilise leading to the phase demixing [28]. Though the as-synthesized powders show a decreasing trend in crystallite size with zirconium content, the sizes are found to be larger in the target due to temperature assisted growth on sintering. The as-synthesized and sintered zirconia XRD patterns shown in Figs. 1(A) and 2 (A), respectively, exhibit amorphous and monoclinic $\left(m-\mathrm{ZrO}_{2}\right)$ crystalline behaviour. Though it is expected that sintering at $1473 \mathrm{~K}$ should transform the amorphous zirconia to tetragonal structure, the duration of sintering is insufficient which results in the monoclinic phase.

In order to quantify the phase composition of sintered ceria-zirconia composition, Rietveld refinement has been done and is shown in Table 3. The ceria synthesis attempted with devoid of any $\mathrm{ZrO}_{2}$ additions $(\mathrm{C} 100)$ results in the formation of $c-\mathrm{CeO}_{2}$ having a cubic unit cell with a $\mathrm{Fm} 3 \mathrm{~m}$ space setting while pure $\mathrm{ZrO}_{2}$ (Z100) leads to the formation of $\mathrm{ZrO}_{2}$ with a monoclinic unit cell with a $\mathrm{P} 42 / \mathrm{nmc}$ space setting. The cerium and zirconium combination preserves the metastable $t$ $\mathrm{ZrO}_{2}$ at high temperatures. The crystallisation of discrete $c-\mathrm{CeO}_{2}$ is witnessed in C75Z25 which has a lower zirconium content. Nonetheless, a gradual increment in the zirconium content with the simultaneously reduced additions of zirconium leads to the crystallisation of both metastable $t-\mathrm{ZrO}_{2}$ and $c-\mathrm{CeO}_{2}$. The phase fractions determined from the refinement results corroborate with experimentally planned precursor concentrations by the virtue of enhanced phase content of $t-\mathrm{ZrO}_{2}$ as noticed in $\mathrm{C} 25 \mathrm{Z75}$ rather than $\mathrm{C} 50 \mathrm{Z5} 5$. The refined lattice data also infers the mutual role of $\mathrm{Ce}^{4+}(0.94 \AA)$ and $\mathrm{Zr}^{4+}$ $(0.74 \AA)$ in the crystallisation behaviour of $c-\mathrm{CeO}_{2}$ and $t-\mathrm{ZrO}_{2} \cdot c-\mathrm{CeO}_{2}$ experience a strong lattice contraction with the incremental zirconium additions which affirms the occupancy of lower sized $\mathrm{Zr}^{4+}$ for the higher sized $\mathrm{Ce}^{4+}$ at the $\mathrm{c}-\mathrm{CeO}_{2}$ lattice.

Fig. 2(B) shows the Raman spectra recorded for the targets to understand the effect of sintering. C100 and C75Z25 show an intense, symmetric $\mathrm{F}_{2 \mathrm{~g}}$ peak at 465 and $466 \mathrm{~cm}^{-1}$, respectively. In comparison to the as-synthesized samples, the $\mathrm{F}_{2 \mathrm{~g}}$ band of $\mathrm{C} 100$ and $\mathrm{C} 75 \mathrm{Z} 25$ display a peak shift towards the higher wavenumber due to the increase in crystallite size upon sintering. The absence of any additional peak other than $F_{2 g}$ in C75Z25 even after sintering indicates the presence of only ceria phase. However, multiple peaks are observed for C50Z50 and C25Z75. The Raman spectrum of C50Z50 exhibits a high intense peak at $469 \mathrm{~cm}^{-1}$ and weak peaks at 247, 315, 599 and $643 \mathrm{~cm}^{-1}$. Generally, tetragonal $\mathrm{ZrO}_{2}$ displays six Raman active modes in Raman spectra [33]. The low intense peaks at 247, 315, 599 and $643 \mathrm{~cm}^{-1}$ are originated from tetragonal $\mathrm{ZrO}_{2}$. The high intense peak at $469 \mathrm{~cm}^{-1}$ shows the presence of cubic phase of ceria which can overlap with the tetragonal zirconia. However, the strong intensity at $469 \mathrm{~cm}^{-1}$ over the rest of the other peaks implies the dominant presence of cubic phase of ceria in C50Z50. Unlike C50Z50, in the case of C25Z75 Raman peaks corresponding to tetragonal zirconia becomes prominent in comparison to the $\mathrm{F}_{2 \mathrm{~g}}$ band of cubic ceria. Thus, even the presence of a lower fraction of cerium ( $25 \mathrm{wt} . \%$ ) stabilizes the zirconia in tetragonal phase. However, Raman peaks observed for sintered Z100 correspond to monoclinic phase in agreement with our XRD calculation [34].

\subsection{Structural characterization of the as-coated samples}

The targets prepared by sintering the compacted pellet were used for the deposition over AISI 304 substrate using EBPVD method. The XRD pattern for the as-coated samples and bare AISI 304 (uncoated) are shown in Fig. 3 (A). The peaks of bare AISI 304 matches with that of ICDD 00-033-0397 and show the presence of both $\gamma$-Fe (austenitic) and $\alpha$-Fe (martensitic) phases $[15,16]$. The presence of $\alpha$-Fe peak even before the coating is induced by the mechanical polishing that has been carried out to enhance the adherence between the coating and the substrate [15]. The cubic fluorite phase observed for the as-coated samples (C100 and C75Z25) matches with that of standard ICDD data (01-081-0792). The absence of additional phases in C75Z25 specifies the doping of $\mathrm{Zr}^{4+}$ in ceria lattice in the as-coated condition. For the coated samples of C50Z50 and C25Z75, cubic ceria and tetragonal zirconia phases are observed. Unlike the target, coated Z100 exhibits only the tetragonal phase. EBPVD is an atom-by-atom evaporation 

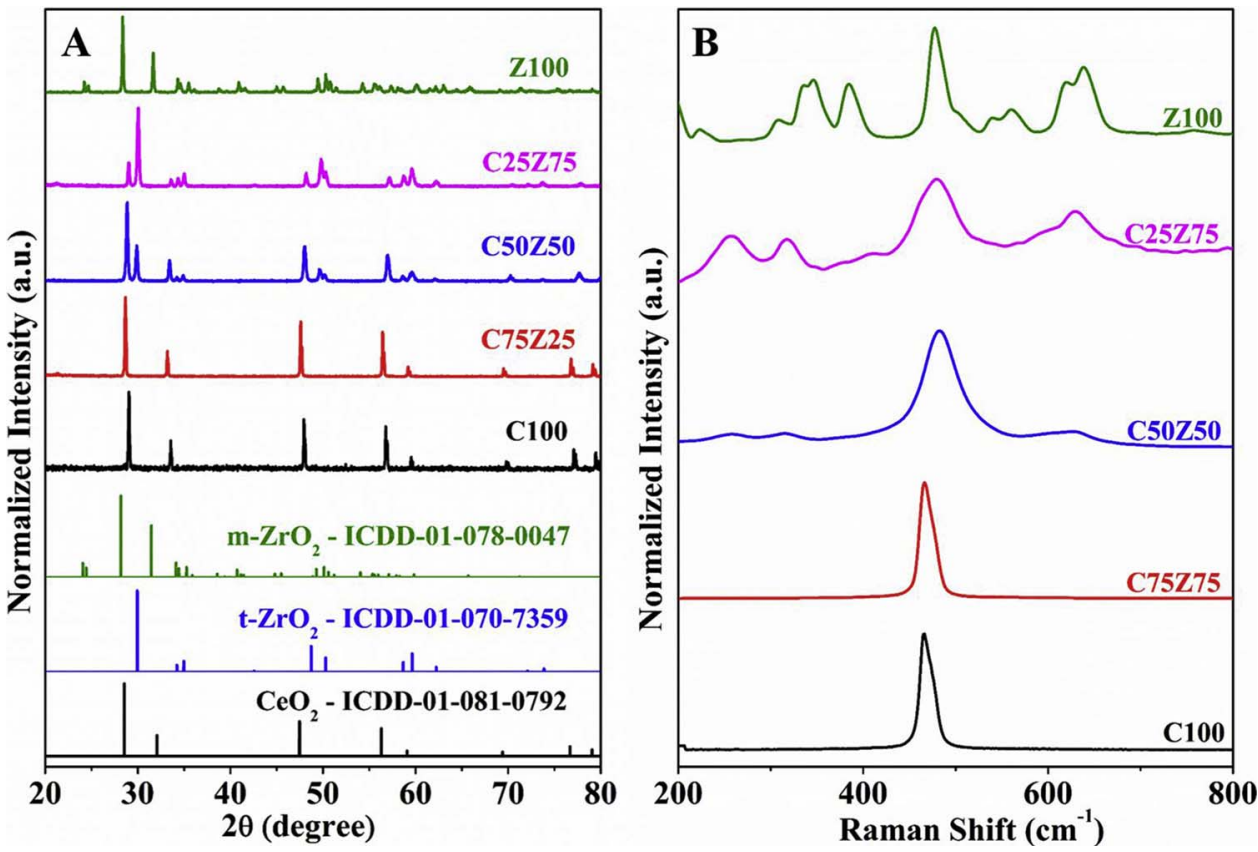

Fig. 2. XRD (A) and Raman (B) spectra for the target.
Table 3

Phase quantities of sintered ceria-zirconia pellets using rietveld refinement.

\begin{tabular}{lll}
\hline \multirow{2}{*}{ Sample } & \multicolumn{2}{l}{ Phase weight fraction (\%) } \\
\cline { 2 - 3 } & $t-\mathrm{ZrO}_{2}$ & $c-\mathrm{CeO}_{2}$ \\
\hline $\mathrm{C} 100$ & - & 100 \\
$\mathrm{C} 75 \mathrm{Z} 25$ & - & 100 \\
$\mathrm{C} 50 \mathrm{Z} 50$ & 16.40 & 83.60 \\
$\mathrm{C} 25 \mathrm{Z75}$ & 86.70 & 13.30 \\
$\mathrm{Z}^{2}$ & 100 & - \\
\hline
\end{tabular}

a refers to $\mathrm{m}-\mathrm{ZrO}_{2}$ in the case of $\mathrm{Z100}$.

technique and the processing parameters such as deposition rate, substrate temperature, vapour incidence angle and substrate rotation may influence the phase formation. In the present work, the deposition rate $(0.2 \mathrm{~nm} / \mathrm{s})$, substrate temperature $(373 \mathrm{~K})$ and rotational speed
(20 rpm) are kept low and constant for all the coatings and hence, the kinetic energy of deposited atom is low so that the atoms are stabilized to metastable tetragonal phase for C50Z50, C25Z75 and Z100 [35,36]. The presence of intense peaks from the substrate posed difficulty in the quantitative analysis of the phases.

The calculated mean crystallite size and lattice parameters are shown in Table 4. Upon increasing the Zr concentration in C75Z25, C50Z50 and C25Z75, the peaks become broader which indicates a reduction in crystallite size. It shows the insignificant effect of the target nature over the crystallite size of the coatings. In comparison to target, the crystallite sizes are found to be smaller and fall in the narrow range of $4.5-7.7 \mathrm{~nm}$. In EBPVD, due to the transfer of the energy from the incident electron beam to the target, the atoms or clusters from the target evaporates and gets deposited over the substrate surface. Since the electron beam provides higher energy for the extra nucleation, and the lower substrate temperature delivers low energy for the diffusion of adatoms at the substrate surface, hence it results in restricting the
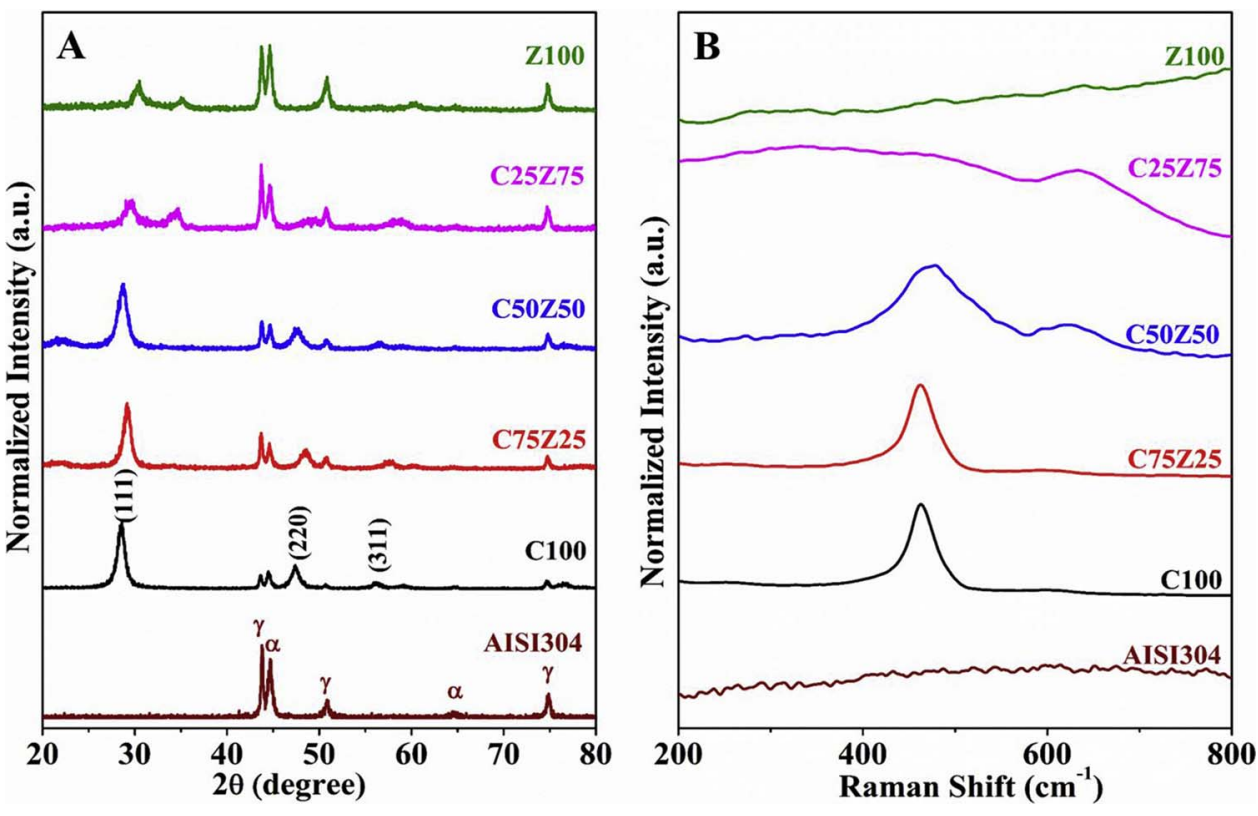

Fig. 3. XRD (A) and Raman (B) spectra for the as coated samples ( $\gamma$-austenitic Fe phase and $\alpha$ - martensitic Fe phase). 
Table 4

Mean crystallite size, lattice constant calculated from XRD spectra.

\begin{tabular}{|c|c|c|c|c|}
\hline \multirow[t]{2}{*}{ Sample Code } & \multicolumn{2}{|c|}{ Mean crystallite size $(\mathrm{nm})^{\mathrm{a}}$} & \multicolumn{2}{|c|}{ Lattice constant (nm) } \\
\hline & As coated & After oxidation & As coated & After oxidation \\
\hline C100 & 7.7 & 29.6 & $0.5446^{\mathrm{a}}$ & $0.5409^{\mathrm{a}}$ \\
\hline C75Z25 & 6.8 & 42.4 & $0.5386^{\mathrm{a}}$ & $0.5440^{\mathrm{a}}$ \\
\hline \multirow[t]{4}{*}{ C50Z50 } & 6.7 & 25.1 & $0.5385^{\mathrm{a}}$ & $0.5389^{\mathrm{a}}$ \\
\hline & & & $0.3697(a)^{b}$ & $0.3607(a)^{b}$ \\
\hline & & & $0.3697(b)^{b}$ & $0.3607(b)^{b}$ \\
\hline & & & $0.5279(c)^{b}$ & $0.5129(\mathrm{c})^{\mathrm{b}}$ \\
\hline \multirow[t]{4}{*}{ C25Z75 } & 4.9 & 24.3 & $0.5381^{\mathrm{a}}$ & $0.5386^{\mathrm{a}}$ \\
\hline & & & $0.3632(a)^{b}$ & $0.3606(a)^{b}$ \\
\hline & & & $0.3632(b)^{b}$ & $0.3606(b)^{b}$ \\
\hline & & & $0.5229(\mathrm{c})^{\mathrm{b}}$ & $0.5180(c)^{b}$ \\
\hline \multirow[t]{3}{*}{$\mathrm{Z} 100$} & 7.5 & 25.5 & $0.3565(a)^{b}$ & $0.5120(a)^{b}$ \\
\hline & & & $0.3565(\mathrm{~b})^{\mathrm{b}}$ & $0.5216(b)^{b}$ \\
\hline & & & $0.5037(\mathrm{c})^{\mathrm{b}}$ & $0.5281(\mathrm{c})^{\mathrm{b}}$ \\
\hline
\end{tabular}

${ }^{a}$ Calculated parameters from $\mathrm{CeO}_{2}$.

b Calculated parameters from $\mathrm{ZrO}_{2}$.

further growth of nucleus eventually leads to smaller crystallite size [37]. The lower intensity of the $\gamma$-Fe peak in the coated samples can be attributed to the transformation of $\gamma$-Fe to $\alpha$-Fe. As a result of strain introduced during the coating process austenitic to martensitic transformation was observed [15].

Raman spectra of the as-coated samples are shown in Fig. 3(B). The $F_{2 g}$ peak of ceria is observed at 462,459 and $469 \mathrm{~cm}^{-1}$ for $\mathrm{C} 100$, C75Z25 and C50Z50, respectively. The defect concentrations of C100, C75Z25 and C50Z50 coated samples calculated using the spatial correlation model are given in Table 2 . The calculated defect concentration values for the coated samples are found to be higher than that of the target. Thus, the physical process of evaporation and redeposition under very low oxygen partial pressure has resulted in the higher defect concentration than that of the target. XRD and Raman spectroscopic analysis indicates that the mean crystallite size of the as-coated samples varies marginally from 6.7 to $7.3 \mathrm{~nm}$ while that of oxygen vacancy concentration varies from $2.1 \times 10^{-21}$ to $3.1 \times 10^{-21} \mathrm{~cm}^{-3}$ due to the presence of zirconium and its subsequent effect on the lattice structure.

\subsection{Oxidation kinetics}

The mass gain as a function of time at $1243 \mathrm{~K}$ for the bare and $\mathrm{xCeO}_{2}-(1-\mathrm{x}) \mathrm{ZrO}_{2}$ coated on AISI 304 is shown in Fig. 4. The square of weight gain per unit area ( $\mathrm{s}$ ) versus time (t) is obtained from the oxidation data is shown in Fig. 5. This can be represented by the equation given below: [38,39]

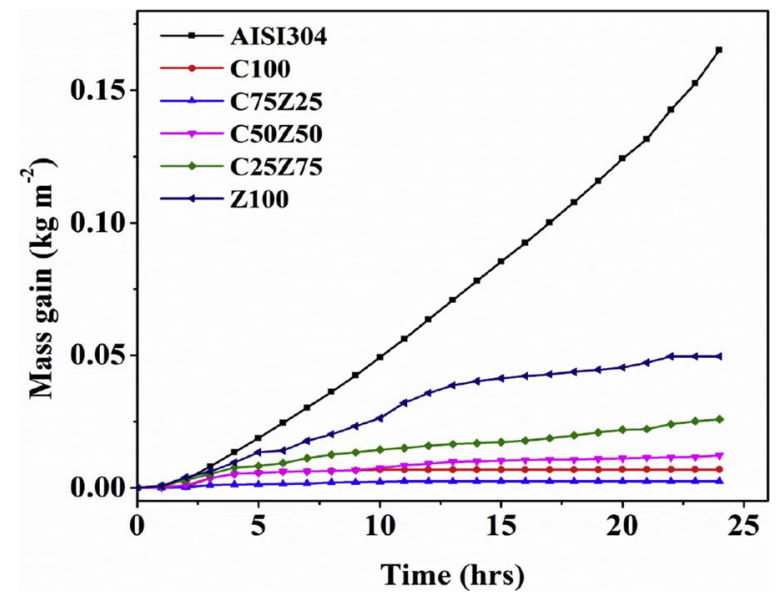

Fig. 4. Mass gain of the oxidized samples at $1243 \mathrm{~K}$ for $24 \mathrm{~h}$.
$\left(\frac{\Delta m}{s}\right)^{2}=k_{p} t$

where $k_{\mathrm{p}}$ is the parabolic rate constant $\left(\mathrm{kg}^{2} \mathrm{~m}^{-4} \mathrm{~s}^{-1}\right)$. The $k_{p}$ value obtained by fitting the experimental data with the least squares method $[38,39]$ is given in Table 5. Weight gain of bare AISI 304 coupon linearly increases with respect to the time and exhibits the highest $k_{p}$ value of $3.5 \pm 0.03 \times 10^{-6} \mathrm{~kg}^{2} \mathrm{~m}^{-4} \mathrm{~s}^{-1}$. In contrast to bare AISI 304 , $\mathrm{xCeO}_{2}-(1-\mathrm{x}) \mathrm{ZrO}_{2}$ coated samples show parabolic oxidation behaviour. The $k_{p}$ values for the samples C100, C75Z25 and C50Z50 are found to be 3-4 orders lower than that of bare AISI 304, indicating the ability of the coating to protect against high temperature. However, the $k_{p}$ values for C25Z75 and Z100 are only 2-3 orders lower than the bare AISI 304. A minimal weight gain was observed for C100, C75Z25 and C50Z50 during the initial 3-4 h of oxidation while C25Z75 and Z100 continued to gain mass even after $24 \mathrm{~h}$. Among all the samples the lowest $k_{p}$ value of $7.9 \pm 0.01 \times 10^{-11} \mathrm{~kg}^{2} \mathrm{~m}^{-4} \mathrm{~s}^{-1}$ is observed for C75Z25. Thus, the C75Z25 sample shows superior oxidation protection than that of pure ceria (C100). On moving from C75Z25 to Z100, the $k_{p}$ value increase with an increase in $\mathrm{Zr}$ content. Though pure zirconia renders weak protection than that of ceria while C75Z25 offered the best protection at a higher temperature.

\subsection{Structural characterization of oxidized samples}

To understand the mechanism of high-temperature oxidation, the oxidized samples have been analysed with XRD, Raman and SEM. The XRD spectra of the oxidized samples at $1243 \mathrm{~K}$ for $24 \mathrm{~h}$ are shown in Fig. 6(A). AISI 304 displayed different XRD pattern after oxidation due to the formation of oxides such as $\mathrm{Mn}_{1.5} \mathrm{Cr}_{1.5} \mathrm{O}_{4}$ (ICDD-00-033-0892), $\mathrm{FeCr}_{2} \mathrm{O}_{4}$ (ICDD-00-034-0140), $\mathrm{Fe}_{2} \mathrm{O}_{3}$ (ICDD-00-033-0664) and $\mathrm{Fe}_{3} \mathrm{O}_{4}$ (ICDD-00-003-0862) along with the little fraction of $\mathrm{Cr}_{2} \mathrm{O}_{3}$ (ICDD-00038-1479). The Gibbs free energy of formation for $\mathrm{Cr}_{2} \mathrm{O}_{3}, \mathrm{MnO}, \mathrm{SiO}_{2}$, $\mathrm{FeO}, \mathrm{Fe}_{3} \mathrm{O}_{4}$ and $\mathrm{NiO}$ are calculated to be $-528.7,-588.5,-657.85$, $-367.4,-360$ and $-257.4 \mathrm{~kJ} \mathrm{~mol}^{-1}$, respectively, for $1 \mathrm{~mol}$ of oxygen to react with a metal to form the corresponding oxide formation

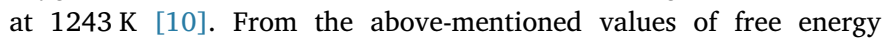
change, it is obvious that $\mathrm{Cr}_{2} \mathrm{O}_{3}$ is favoured but the movement of $\mathrm{Mn}$ and $\mathrm{Fe}$ ions via the grain boundary of initially formed $\mathrm{Cr}_{2} \mathrm{O}_{3}$ layer results in the formation of $\mathrm{Mn}_{1.5} \mathrm{Cr}_{1.5} \mathrm{O}_{4}, \mathrm{FeCr}_{2} \mathrm{O}_{4}, \mathrm{Fe}_{2} \mathrm{O}_{3}$ and $\mathrm{Fe}_{3} \mathrm{O}_{4}$. In oxidized AISI 304, the existence of $\mathrm{Fe}-\mathrm{Cr}$ alloy peak indicates the formation of weakly adherent porous oxide scale leading to spallation of oxide scale in the later stages of the oxidation [4]. In C100, C75Z25 and C50Z50, the presence of ceria has been observed even after oxidation due to adherent and dense nature of the coating. But the intensity of protective $\mathrm{CeO}_{2}-\mathrm{ZrO}_{2}$ coating is reduced significantly in C25Z75. For $\mathrm{C} 100$ and $\mathrm{C75Z25}$, the intensity of oxides such as $\mathrm{FeCr}_{2} \mathrm{O}_{4}$, $\mathrm{Mn}_{1.5} \mathrm{Cr}_{1.5} \mathrm{O}_{4}, \mathrm{Fe}_{3} \mathrm{O}_{4}$ and $\mathrm{Fe}_{2} \mathrm{O}_{3}$ are found to be significantly lower with respect to bare AISI 304. For C50Z50, the intensity of iron oxides, $\mathrm{FeCr}_{2} \mathrm{O}_{4}$ and $\mathrm{Mn}_{1.5} \mathrm{Cr}_{1.5} \mathrm{O}_{4}$ slightly increased in comparison to $\mathrm{C} 100$ and C75Z25. In comparison to C100, C75Z25 and C50Z50, the intensity of iron oxides, $\mathrm{FeCr}_{2} \mathrm{O}_{4}$ and $\mathrm{Mn}_{1.5} \mathrm{Cr}_{1.5} \mathrm{O}_{4}$ are increased in larger extent for $\mathrm{C} 25 \mathrm{Z75}$ and $\mathrm{Z100.}$

Raman spectra for the samples after oxidation are shown in Fig. 6(B). The characteristic Raman peak for ceria was observed at $465 \mathrm{~cm}^{-1}$ for C100 and C75Z25. But for C50Z50 and C25Z75 sample exhibit the peak at 477 and $479 \mathrm{~cm}^{-1}$, respectively. The calculated oxygen vacancy concentrations for the oxidized samples are shown in Table 2. In comparison to the as-coated counterpart, the Raman peaks of the oxidized samples become narrower and are shifted to higher wavenumber which implies a reduction in oxygen vacancy concentration upon oxidation. Similarly, the Raman peak around $606 \mathrm{~cm}^{-1}$ associated with the presence of oxygen vacancy vanishes due to the oxidation of $\mathrm{Ce}^{3+}$ to $\mathrm{Ce}^{4+}$ upon oxidation though present in the as coated samples. A similar observation of temperature induced modification of defect concentration was reported by Bouchaud et al., [12]. 

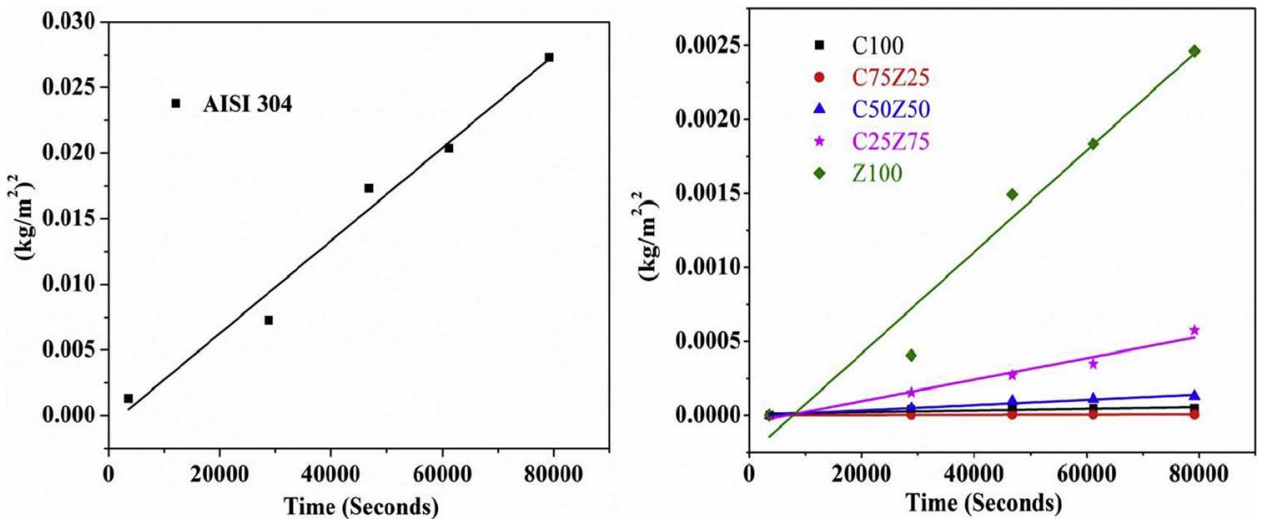

Fig. 5. The square variation of mass per surface area $\left(\mathrm{kg} / \mathrm{m}^{2}\right)^{2}$ versus oxidation time (t) for oxidized samples.
Table 5

Rate constant of the coated samples oxidized at $1243 \mathrm{~K}$ for $24 \mathrm{~h}$.

\begin{tabular}{ll}
\hline Sample code & Rate constant, $\mathrm{k}_{\mathrm{p}}\left(\mathrm{kg}^{2} \mathrm{~m}^{-4} \mathrm{~s}^{-1}\right)$ \\
\hline AISI 304 & $3.5 \pm 0.03 \times 10^{-6}$ \\
C100 & $1.8 \pm 0.02 \times 10^{-10}$ \\
C75Z25 & $7.9 \pm 0.01 \times 10^{-11}$ \\
C50Z50 & $5.8 \pm 0.02 \times 10^{-10}$ \\
C25Z75 & $7.3 \pm 0.05 \times 10^{-9}$ \\
Z100 & $3.4 \pm 0.04 \times 10^{-8}$ \\
\hline
\end{tabular}

For AISI 304 the chromia peaks are visible at $555 \mathrm{~cm}^{-1}$ due to more oxygen availability at the substrate surface. But the chromia peak was absent for the other samples which may be due to the presence of very thin chromia layer along the interface of substrate/coating. The optimum oxygen vacancy concentration in C75Z25facilitates the early formation of chromia by facilitating the passage of oxygen through the coating during the initial period of oxidation [15]. The presence of higher oxygen concentration in C50Z50 than C100 or C75Z25 could facilitate the formations of other oxides due to more oxygen supply.

In order to quantify the oxidation state of cerium after oxidation, XPS studies were carried out. Due to the spin-orbit coupling of Ce $3 \mathrm{~d}_{5 / 2}$ and $\mathrm{Ce} 3 \mathrm{~d}_{3 / 2}$, Ce $3 \mathrm{~d}$ spectra exhibits multiple peaks which can be deconvoluted into peaks marked $\mathrm{v}_{\mathrm{o}}, \mathrm{v}, \mathrm{v}^{\prime}, \mathrm{v}^{\prime \prime}, \mathrm{v}^{\prime \prime \prime}, \mathrm{u}_{\mathrm{o}}, \mathrm{u}, \mathrm{u}^{\prime}, \mathrm{u}^{\prime \prime}$ and $\mathrm{u}^{\prime \prime \prime}$ corresponding to differing binding energy $[36,40,41]$. The binding energies for $\mathrm{Ce}^{3+}$ are found to be $880.2\left(\mathrm{~V}_{0}\right), 885.0(\mathrm{~V}), 899.0\left(\mathrm{U}_{0}\right)$ and $903.50 \mathrm{eV}$ (Ú) while that of $\mathrm{Ce}^{4+}$ gives rise to $882.1(\mathrm{~V}), 888.1\left(\mathrm{~V}^{\prime \prime}\right)$, $898.0\left(\mathrm{~V}^{\prime \prime \prime}\right), 900.9(\mathrm{U}), 906.4\left(\mathrm{U}^{\prime \prime}\right)$ and $916.3\left(\mathrm{U}^{\prime \prime \prime}\right) \mathrm{eV}$. The concentration of $\mathrm{Ce}^{3+}$ can be calculated by using the formula given below.

$\left[C e^{3+}\right]=\frac{A_{v 0}+A_{v^{\prime}}+A_{u 0}+A_{u^{\prime}}}{\sum A_{i}}$

where $A_{v 0}, A_{v^{\prime}}, A_{u 0}, A_{u^{\prime}}$, are the area under characteristic peaks of $\mathrm{Ce}^{3+}$ and $A_{i}$ is an integrated area for peak ' $i$ '. The experimental and deconvoluted peaks of Ce3d core level spectra for C100, C75Z25 and C50Z50 are shown in Fig. 7. From the calculated area under the peaks, the $\mathrm{Ce}^{3+}$ concentration has been found to be 13,18 and $23 \%$ for C100, C75Z25 and C50Z50, respectively. The observation is in agreement with our Raman results with respect to the presence of oxygen vacancy. To understand the nature of local environment, XPS spectra of O1s was recorded for C100 and C50Z50. The experimental and deconvoluted peaks of O1s core level spectra are shown in Fig. 8. Martinez et al. attributed the deconvoluted $\mathrm{O} 1$ peak at $529.6 \pm 0.2 \mathrm{eV}$ to the lattice oxygen present in the coating. The second deconvoluted peak $\mathrm{O} 2$ appeared at $531.6 \pm 0.2 \mathrm{eV}$ corresponds to the defective oxides present in the coating [42]. The retention of relatively larger fraction of defect oxide concentration can be noticed in C50Z50 that of C100 matching well with our $\mathrm{Ce}^{3+}$ and defect quantification (Table. 2).

SEM surface image and elemental mapping of the oxidized C100, C75Z25, C50Z50 and C25Z75 samples are shown in Figs. 9 and 10,
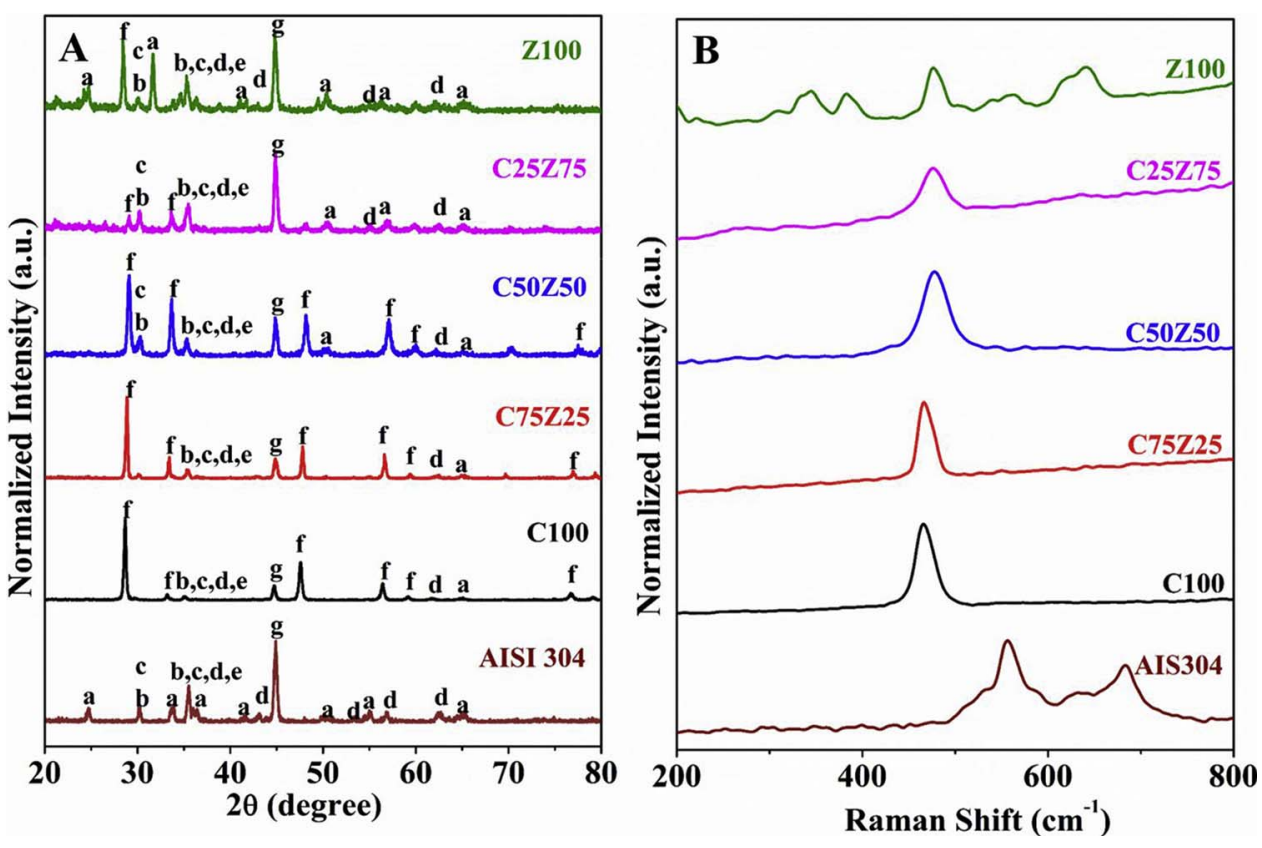

Fig. 6. XRD (A) and Raman (B) spectra of oxidized samples at $1243 \mathrm{~K}$ for $24 \mathrm{~h}\left(\mathrm{a}-\mathrm{Cr}_{2} \mathrm{O}_{3}, \mathrm{~b}-\mathrm{Fe}_{3} \mathrm{O}_{4}\right.$, c$\mathrm{Fe}_{2} \mathrm{O}_{3}, \mathrm{~d}-\mathrm{Mn}_{1.5} \mathrm{Cr}_{1.5} \mathrm{O}_{4}$, e- $-\mathrm{FeCr}_{2} \mathrm{O}_{4}, \mathrm{f}-\mathrm{CeO}_{2}$ or $\mathrm{ZrO}_{2}$, g$\mathrm{Fe}-\mathrm{Cr}$ ). 

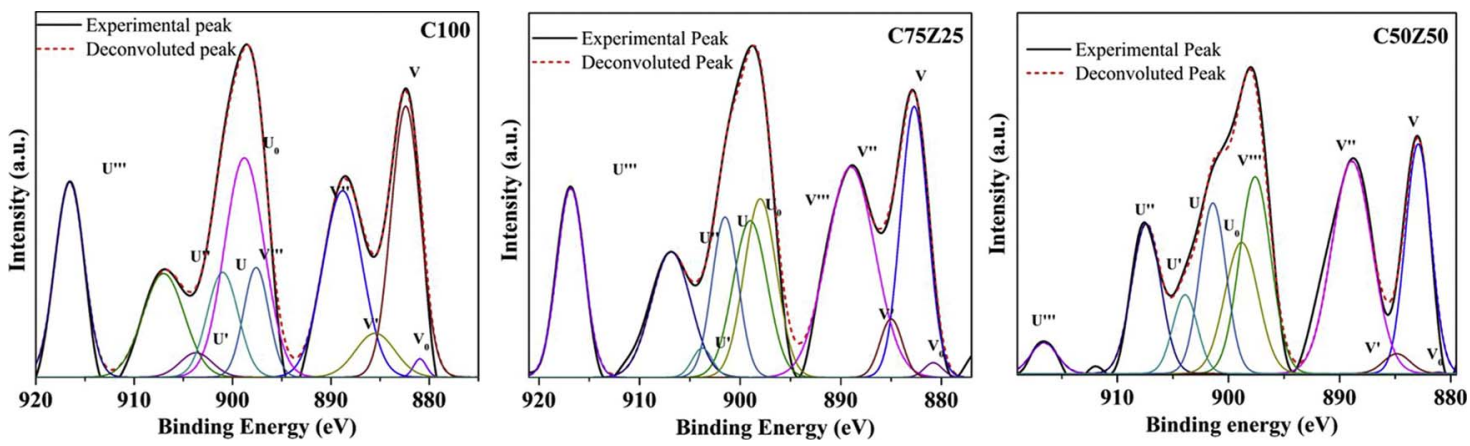

Fig. 7. Experimental and deconvoluted Ce3d XPS spectra for C100, C75Z25 and C50Z50.

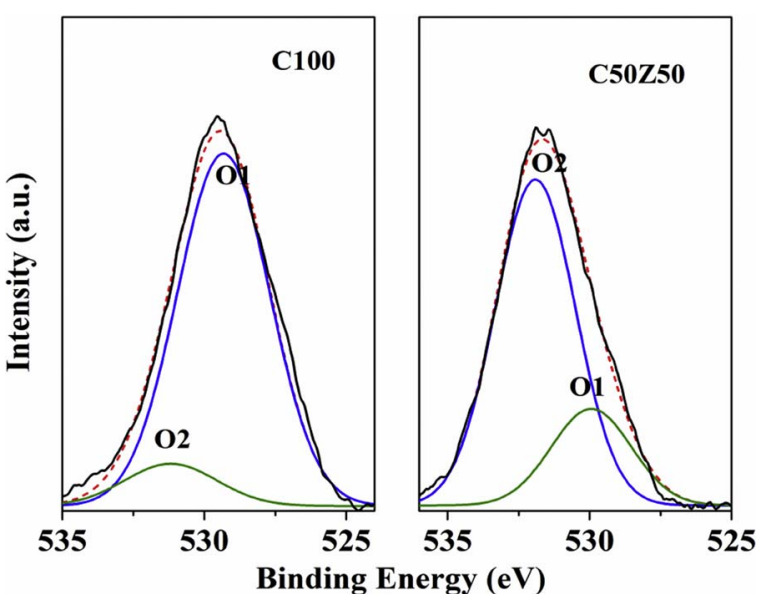

Fig. 8. Experimental and deconvoluted XPS spectra for O1 $s$ peak of C100 and C50Z50.

respectively. The oxidized samples C100, C75Z25, and C50Z50 show a continuous coating at the surface. X-ray elemental mapping shows the presence of $\mathrm{Ce}$ in $\mathrm{C} 100$ and $\mathrm{C75Z25}$ while $\mathrm{Zr}$ and Ce is observed at the surface for C50Z50 in addition to $\mathrm{Cr}, \mathrm{Mn}$ and Fe. Presence of $\mathrm{Cr}$, Mn and $\mathrm{Fe}$ on the surface indicates the outward diffusion of the elements from the base alloy upon oxidation matching well with our XRD results. Thus the presence of coating modulates the oxygen partial pressure to enable the diffusion of chromium in the early stages of the oxidation followed by the other elements. In comparison, a lower concentration of $\mathrm{Cr}, \mathrm{Mn}$, and $\mathrm{Fe}$ is noticed at the surface of $\mathrm{C100}$ and C75Z25 than that of C50Z50. It may arise from the higher oxygen partial pressure in C50Z50 due to larger oxygen vacancy concentration (Table. 2) at the interface between the substrate and the coating which results in the formation of protective chromia at the interface $[10,15]$. A flake-like structure is observed in C25Z75 which is similar to the surface morphology of the uncoated AISI 304 reported by us [15]. But, C25Z75 exhibited a higher $\mathrm{Mn}, \mathrm{Cr}$, and $\mathrm{Fe}$ content on the surface than $\mathrm{Ce}$ and $\mathrm{Zr}$ due to the formation of $\mathrm{Mn}_{1.5} \mathrm{Cr}_{1.5} \mathrm{O}_{4}$ and $\mathrm{FeCr}_{2} \mathrm{O}_{4}$. The presence of cracks in $\mathrm{C} 25 \mathrm{Z75}$ films enriches the availability of oxygen at the substrate/coating interface unlike in the other samples. The availability of more oxygen eases the diffusion of elements and thereby rendering the coating less protective. The higher rate constant (Table 5) and the presence of larger fraction of $\mathrm{Mn}_{1.5} \mathrm{Cr}_{1.5} \mathrm{O}_{4}$ and $\mathrm{FeCr}_{2} \mathrm{O}_{4}$ (Fig. 6A) supports the above observation.

SEM cross sectional image and elemental mapping of the oxidized C100, C75Z25, C50Z50 and C25Z75 samples are shown in Figs. 11 and 12, respectively. From the cross-sectional SEM images, triple layer (substrate/oxide layer/coating) can be observed for C100, C75Z25, and C50Z50 (Fig. 11). The oxide layer (predominantly chromia) is observed in between the substrate and the coating for C100, C75Z25, and C50Z50. C75Z25 oxide scale is relatively thin in comparison to C100 and C50Z50 while C25Z75 shows the thickest oxide layer. The presence of uniformly distributed elemental zirconium and cerium can be seen
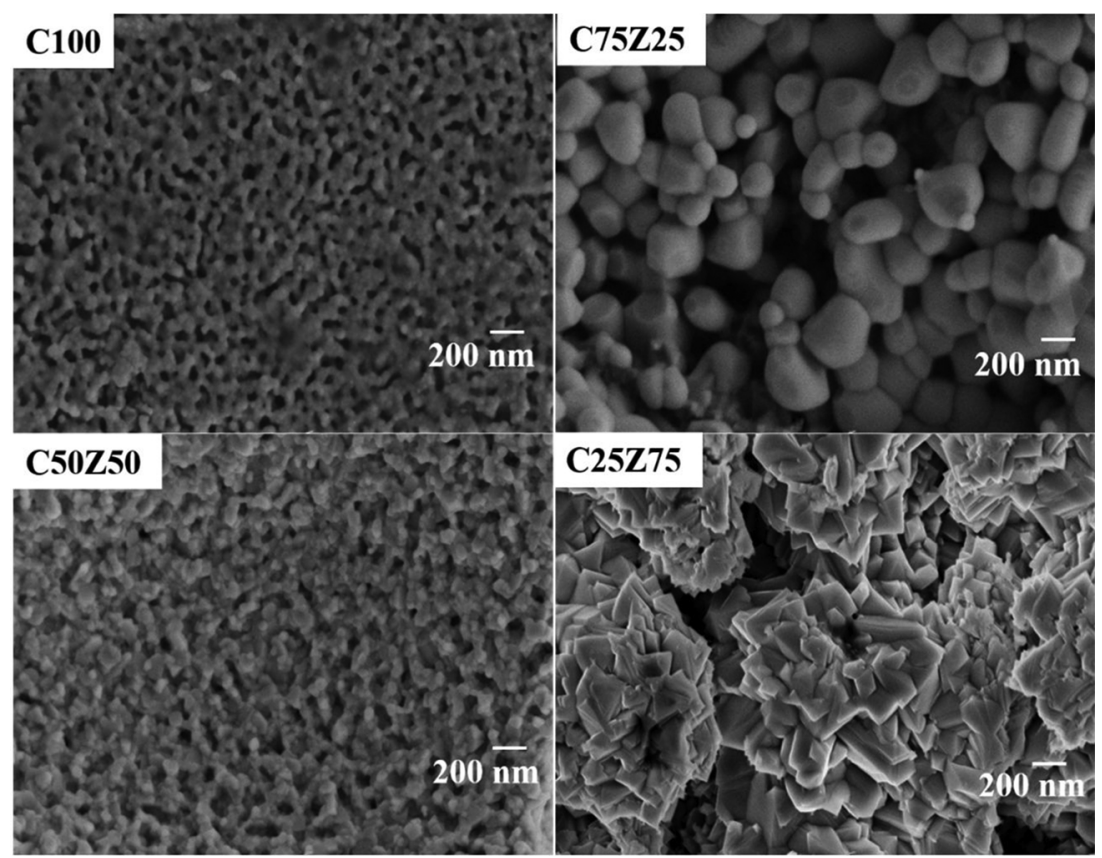

Fig. 9. SEM surface images of the samples oxidized at $1243 \mathrm{~K}$ for $24 \mathrm{~h}$.

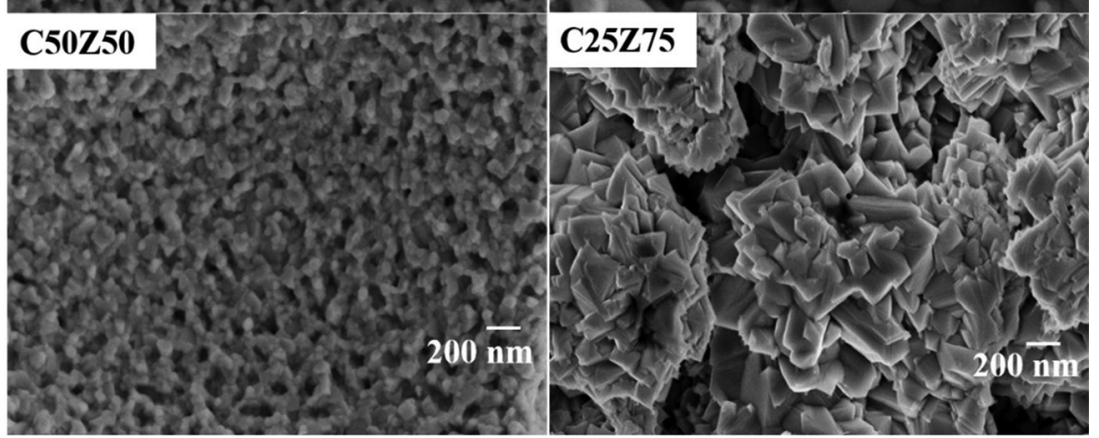




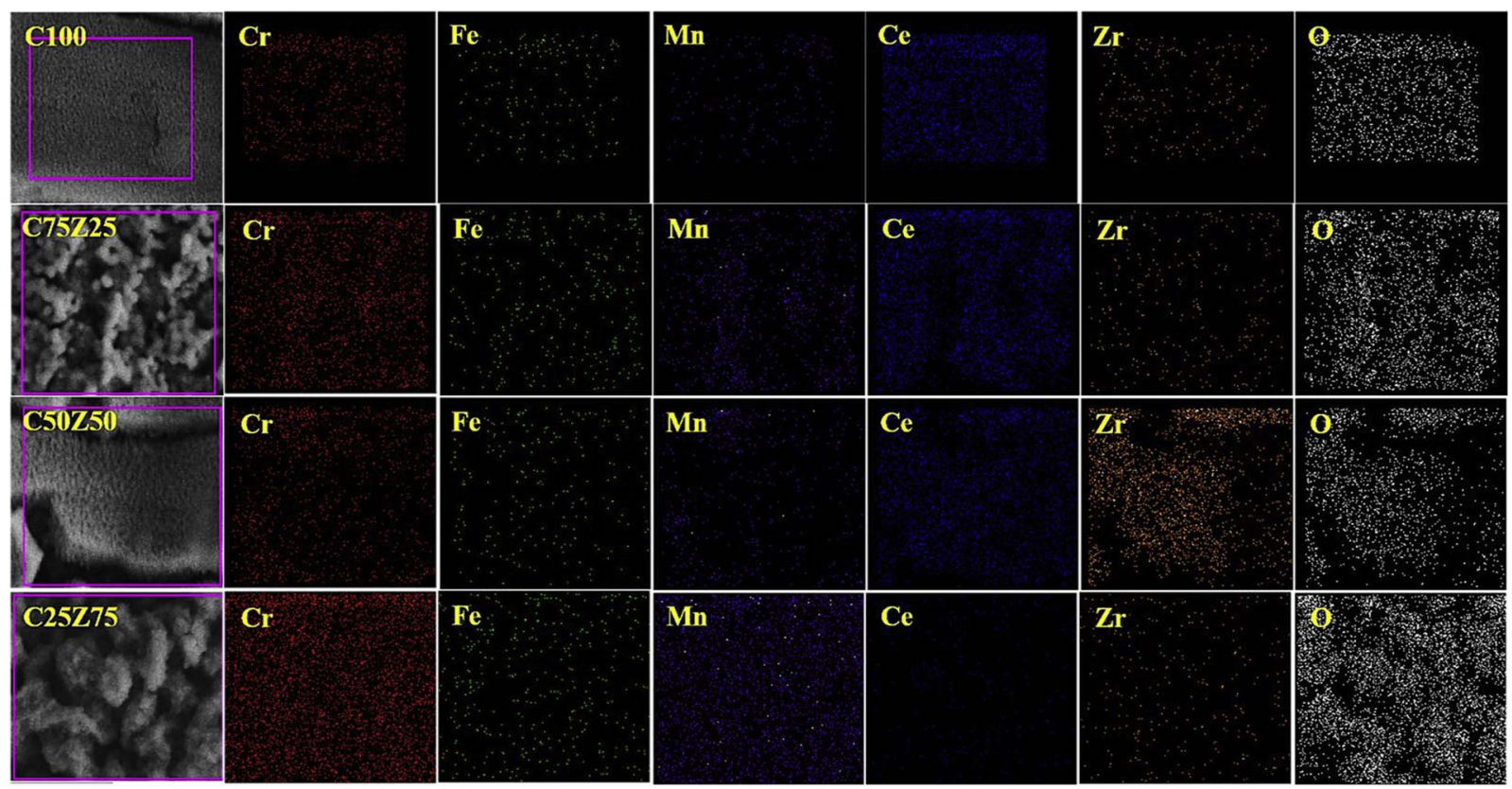

Fig. 10. Surface elemental mapping of oxidized samples (square box represents the area used in the analysis).

from the X-ray mapping. However, a dense distribution of $\mathrm{Cr}$ observed in C100 \& C75Z25 gets reduced in C50Z50 \& C25Z75 while exhibiting an opposite trend for Fe and Mn. X-ray mapping clearly indicates the ease of Fe and Mn migration across the coating in the form of metal oxides matching with our results. Hence in C75Z25 and C100, the optimal oxygen vacancy results in less oxygen partial pressure at the substrate/coating interface leading to the formation of thin chromia due to the higher negative free energy of formation compared to other oxides. However, in C50Z50 the presence of more oxygen vacancy lead to a relatively thicker oxide scale due to high oxygen partial pressure. Bouchaud et al. report on ceria coated Ni based super alloy oxidized at $1373 \mathrm{~K}$ could be compared to our present work. In both the cases, the formation of protective oxides $\left(\mathrm{Cr}_{2} \mathrm{O}_{3}\right.$ or $\left.\mathrm{Al}_{2} \mathrm{O}_{3}\right)$ mainly depends on the oxygen vacancy mediated oxygen partial pressure available at the substrate/coating interface [13]. In C25Z75, cracks in the film appear in the course of oxidation leads to more oxygen inflow and uncontrolled diffusion of $\mathrm{Cr}, \mathrm{Fe}$ and $\mathrm{Mn}$ result in the formation of more oxides and disruption of entire coating. Moreover, Scardi et al. and Nandi et al. reported that the increasing $\mathrm{Zr}$ content in ceria-zirconia results in the decrease in thermal expansion coefficient. They also reported that the increase in temperature leads to the decrease in the thermal coefficient of expansion $[43,44]$. Hence, the crack in ceria-zirconia composites (C25Z75) could be attributed to the change in thermal expansion coefficient with increasing $\mathrm{Zr}$ content. Eventually at $1243 \mathrm{~K}$, the lattice of zirconia shrinks which leads to the excessive compressive stress and crack formation in the C25Z75 film. The SEM images indicate the

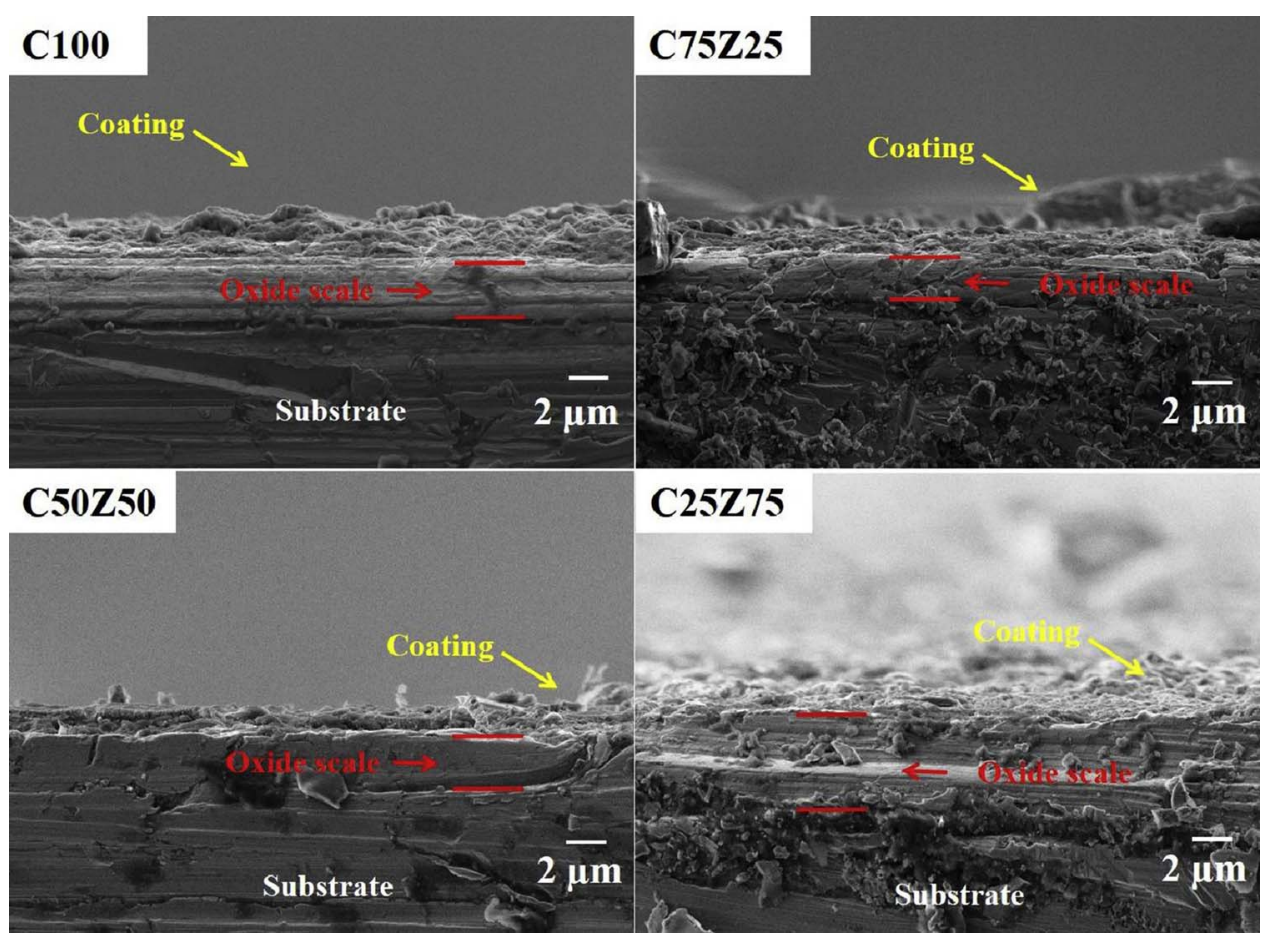

Fig. 11. SEM cross sectional images of oxidized samples at $1243 \mathrm{~K}$ for $24 \mathrm{~h}$. 


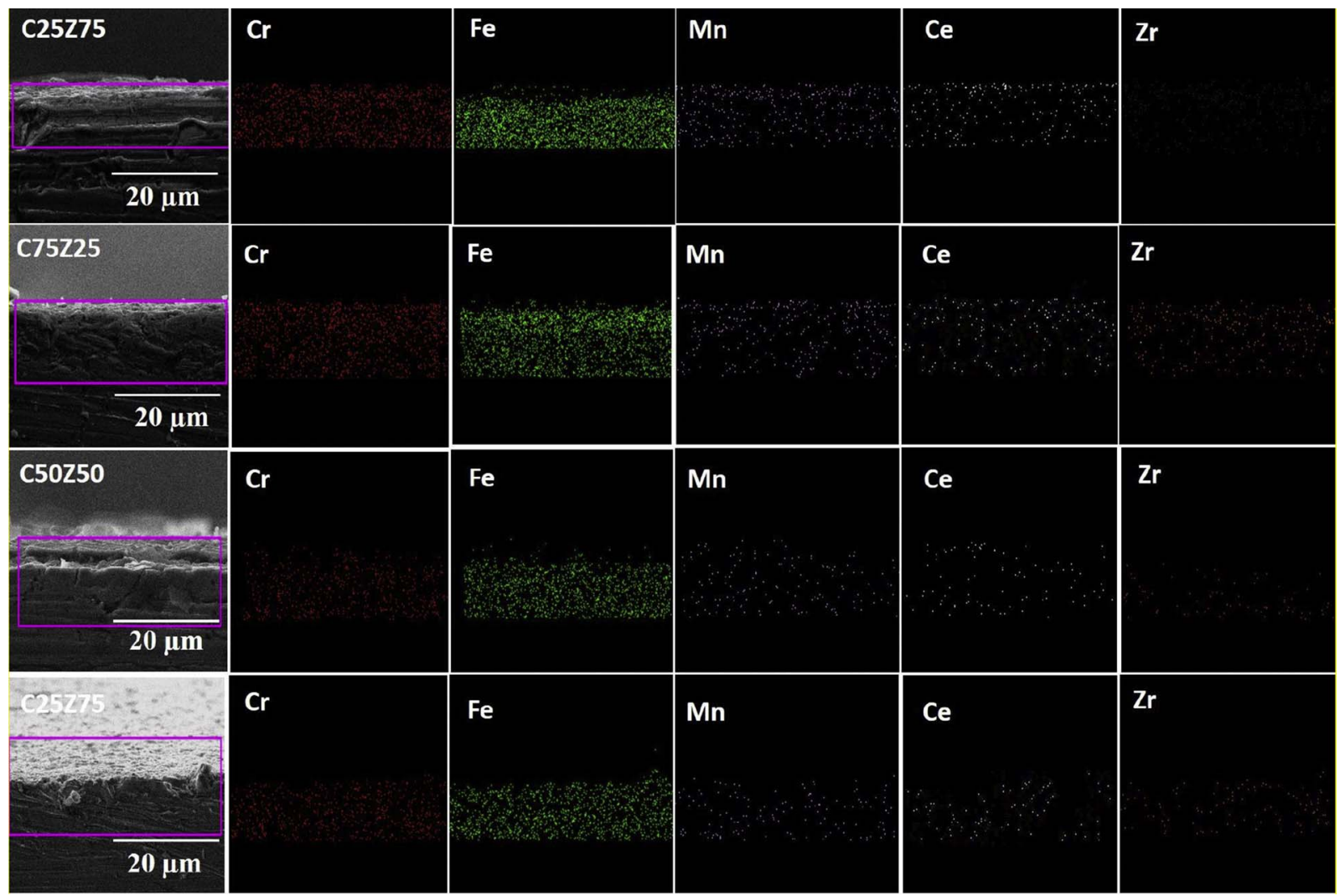

Fig. 12. A representative cross sectional elemental mapping from the marked area for the oxidized C100 and C75Z25.

protective nature of C100, C75Z25, and C50Z50 coatings. Hence, C25Z75 provides inefficient protection for AISI 304 at $1243 \mathrm{~K}$.

\section{Conclusions}

The structural parameters of ceria-zirconia samples tuned by EBPVD play a significant role in the high temperature oxidation protection of AISI 304. The as-coated C100 and C75Z25 samples have a single cubic phase similar to that of the sintered targets. The crystallite size of ascoated samples remains the same due to the EBPVD processing parameters. The oxygen vacancy of as-coated samples such as C100, C75Z25 and C50Z50 is increased significantly due to the incorporation of $\mathrm{Zr}^{4+}$ ions. The oxidation protection of C100, C75Z25 and C50Z50 Exhibits 3-4 orders better than the bare AISI304. The oxidation protection of C75Z25 is superior due to the presence of optimum oxygen vacancy. During oxidation, the oxygen vacancy generated by $\mathrm{Zr}^{4+}$ ions plays an important role in the protection of AISI 304 against oxidation at $1243 \mathrm{~K}$.

\section{Acknowledgements}

The authors thank the financial support from DST-SERB (SR/FTP/ ETA-01/07/2011) fast track scheme for Young scientist, India. Also, the authors wish to thank the Central Instrumentation Facility (CIF) and Central Maintenance Workshop (CMW), Pondicherry University for the sample preparation and characterization. The authors also thank Mr. P. Arunkumar and Mr. M. Sribalaji for the valuable suggestions and discussions.

\section{References}

[1] S. Seal, S.K. Bose, S.K. Roy, Improvement in the oxidation behavior of austenitic stainless steels by superficially applied, cerium oxide coatings, Oxid. Met. 41 (1994) 139-178.
[2] A.M. Huntz, Diffusion in growing oxide scale, J. Phys. III 5 (1995) 1729-1757.

[3] N. Karimi, F. Riffard, F. Rabaste, S. Perrier, R. Cueff, C. Issartel, H. Buscail, Characterization of the oxides formedat $1000^{\circ} \mathrm{C}$ on the AISI 304 stainless steel by Xray diffraction and infrared spectroscopy, Appl. Surf. Sci 254 (2008) 2292-2299.

[4] F. Riffard, H. Buscail, E. Caudron, R. Cueff, C. Issartel, S. Perrier, Yttrium sol-gel coating effects on the cyclic oxidation behaviour of 304 stainless steel, Corros. Sci. 45 (2003) 2867-2880.

[5] M. Stan, Y.T. Zhu, H. Jiang, D.P. Butt, Kinetics of oxygen removal from ceria, J. Appl. Phys. 95 (2004) 3358-3361.

[6] J. Stringer, The reactive element effect in high-temperature corrosion, Mater. Sci. Eng. A 120 (1989) 129-137.

[7] F.J. Pérez, M.J. Crisóbal, M.P. Hierro, G. Arnau, J. Botella, Corrosion protection of low nickel austenitic stainless steel by yttrium and erbium-ion implantation against isothermal oxidation, Oxid. Met. 54 (2000) 87-101.

[8] S. Patil, S.C. Kuiry, S. Seal, Nanocrystalline ceria imparts better high-temperature, Proc. R. Soc. A 460 (2004) 3569-3587.

[9] S. Patil, S.C. Kuiry, S. Seal, R. Vanfleet, Synthesis of nanocrystalline ceria particles for high temperature oxidation resistant coating, J. Nanopart. Res. 4 (2002) 433-438.

[10] R. Thanneeru, S. Patil, S. Deshpande, S. Seal, Effect of trivalent rare earth dopants in nanocrystalline ceria coatings for high-temperature oxidation resistance, Acta Mater. 55 (2007) 3457-3466.

[11] A. Paúl, J.A. Odriozola, Development of a modified CVD coating process for the enhancement of the high temperature oxidation resistance of $\mathrm{Cr}_{2} \mathrm{O}_{3}$ and $\mathrm{Al}_{2} \mathrm{O}_{3}$ forming alloys, Mater. Sci. Eng. A 300 (2001) 22-33.

[12] B. Bouchaud, J. Balmain, G. Bonnet, F. Pedraza, Optimizing structural and compositional properties of electrodeposited ceria coatings for enhanced oxidation resistance of a nickel-based superalloy, Appl. Surf. Sci. 268 (2013) 218-224.

[13] F. Pedraza, J. Balmain, G. Bonnet, B. Bouchaud, Novel concept of functional oxide coatings providing enhanced oxidation resistance to Ni-based superalloys, Mater. Res. Bull. 49 (2014) 384-387.

[14] H.F. Lopez, H. Zhang, Nanoceria coating imperfections and their effect on the high temperature oxidation resistance of AISI 304 stainless steel, J. Mater. Sci. 49 (2014) 277-286.

[15] R. Aadhavan, K. Suresh Babu, Effect of EBPVD coated nanoceria thickness on the isothermal oxidation of AISI 304 stainless steel, Surf. Coat. Technol. 272 (2015) $395-402$.

[16] R. Aadhavan, K. Suresh Babu, Role of oxygen vacancy tuning in EBPVD deposited $\mathrm{La}_{\mathrm{x}} \mathrm{Ce}_{1-\mathrm{x}} \mathrm{O}_{2-\delta}$ films in high temperature oxidation protection, RSC Adv. 5 (2015) 83538-83545.

[17] J. Kašper, R.D. Monte, P. Fornasiero, M. Graziani, H. Bradshaw, C. Norman, Dependency of the oxygen storage capacity in Zirconia-ceria solid solutions upon textural properties, Top. Catal. 16-17 (2001) 83-87.

[18] J. Deng, Y. Zhou, Y. Cui, L. Lan, J. Wang, S. Yuan, Y. Chen, The influence of $\mathrm{H}_{2} \mathrm{O}_{2}$ on 
the properties of $\mathrm{CeO}_{2}-\mathrm{ZrO}_{2}$ mixed oxides, J. Mater. Sci. 52 (2017) 5242-5255.

[19] B.M. Reddy, A. Khan, Nanosized $\mathrm{CeO}_{2}-\mathrm{SiO}_{2}, \mathrm{CeO}_{2}-\mathrm{TiO}_{2}$, and $\mathrm{CeO}_{2}-\mathrm{ZrO}_{2}$ mixed oxides: influence of supporting oxide on thermal stability and oxygen storage properties of ceria, Catal. Surv. Asia 9 (2005) 155-171.

[20] M. Yashima, Some recent developments in the atomic-scale characterization of structural and transport properties of ceria-based catalysts and ionic conductors, Catal. Today 253 (2015) 3-19.

[21] R.D. Monte, J. Kašper, Nanostructured $\mathrm{CeO}_{2}-\mathrm{ZrO}_{2}$ mixed oxides, J. Mater. Chem. 15 (2005) 633-648.

[22] M.V.G. Pirovano, A. Hofmann, J. Saucer, Oxygen vacancies in transition metal and rare earth oxides: current state of understanding and remaining challenges, Surf. Sci. Rep. 62 (2007) 219-270.

[23] S. Liu, X. Wu, D. Weng, R. Ran, Ceria-based catalysts for soot oxidation: a review, J. Rare Earth 33 (2015) 567-590.

[24] A. Trovarelli, P. Fornasiero, Catalysis by Ceria and Related Materials, second ed., Imperial College Press, London, 2013.

[25] M. Kuhn, S.R. Bishop, J.L.M. Rupp, H.L. Tuller, Structural characterization and oxygen nonstoichiometry of ceria-zirconia $\left(\mathrm{Ce}_{1-\mathrm{x}} \mathrm{Zr}_{\mathrm{x}} \mathrm{O}_{2-\delta}\right)$ solid solutions, Acta Mater. 61 (2013) 4277-4288.

[26] K. Kenevey, F. Valdivieso, M. Soustelle, M. Pijolat, Thermal stability of Pd or Pt loaded $\mathrm{Ce}_{0.68} \mathrm{Zr}_{0.32} \mathrm{O}_{2}$ and $\mathrm{Ce}_{0.50} \mathrm{Zr}_{0.50} \mathrm{O}_{2}$ catalyst materials under oxidising conditions, Appl. Catal. B Environ. 29 (2001) 93.

[27] S. Deshpande, S. Patil, S.V.N.T. Kuchibatla, S. Seal, Size dependency variation in lattice parameter and valency states in nanocrystalline cerium oxide, Appl. Phys. Lett. 87 (2005) 133113.

[28] C. Bozo, F. Gaillard, N. Guilhaume, Characterisation of ceria-zirconia solid solutions after hydrothermal ageing, Appl. Catal. A-Gen. 220 (2001) 69-77.

[29] F. Zhang, C. Chen, J.C. Hanson, R.D. Robinson, I.P. Herman, S. Chan, J. Am, Ceram. Soc. 89 (2006) 1028-1036.

[30] I. Kosacki, T. Suzuki, H.U. Anderson, P. Colomban, Raman scattering and lattice defects in nanocrystalline $\mathrm{CeO}_{2}$ thin films, Solid State Ion. 149 (2002) 99-105.

[31] Z. Yang, Y. Wei, Z. Fu, Z. Lu, K. Hermansson, Facilitated vacancy formation at Zrdoped ceria (111) surfaces, Surf. Sci. 602 (2008) 1199-1206.

[32] G. Balducci, J. Kašper, P. Fornaseiro, M. Graziani, M.S. Islam, Surface and reduction energetics of the $\mathrm{CeO}_{2}-\mathrm{ZrO}_{2}$ catalysts, J. Phys. Chem. B 102 (1998) 557-561.
[33] B.M. Reddy, A. Khan, Y. Yamada, T. Kobayashi, S. Loridant, J. Volta, Raman and Xray photoelectron spectroscopy study of $\mathrm{CeO}_{2}-\mathrm{ZrO}_{2}$ and $\mathrm{V}_{2} \mathrm{O}_{5} / \mathrm{CeO}_{2}-\mathrm{ZrO}_{2}$ catalysts, Langmuir 19 (2003) 3025-3030.

[34] V.G. Keramidas, W.B. White, Raman scattering study of the crystallization and phase transformations of $\mathrm{ZrO}_{2}$, J. Am. Ceram. Soc. 57 (1974) 22-24.

[35] D.S. Rao, K. Valleti, S.V. Joshi, G.R. Janardhan, Processing-Structure-property relationships in electron beam physical vapor deposited yttria stabilized zirconia coatings, J. Vac. Sci. Technol. A 29 (2011) 031501-031508.

[36] G. Witz, V. Shklover, W. Steurer, S. Bachegowda, H. Bossmann, Phase evolution in yttria stabilized zirconia thermal barrier coatings studied by rietveld refinement of X-ray powder diffraction patterns, J. Am. Ceram. Soc. 90 (2007) 2935-2940.

[37] P. Arunkumar, R. Ramaseshan, S. Dash, J. Basu, T.R. Ravindran, S. Balakumar, K.S. Babu, Texturing of pure and doped $\mathrm{CeO}_{2}$ thin films by EBPVD through target engineering, RSC Adv. 4 (2014) 33338-33346.

[38] A. Movahedi-Rad, S.S. Pelaseyed, M. Attarian, R. Shokrallahzadeh, Oxidation behaviour of AISI 321, AISI 316, and AISI 409 stainless steels: kinetic thermodynamic, and diffusion studies, J. Mater. Res. 14 (2016) 2088-2096.

[39] V. Viswanathan, R. Filmalter, S. Patil, S. Deshpande, S. Seal, High-Temperature oxidation behaviour of solution precursor plasma sprayed nanoceria coating on martensitic steels, J. Am. Ceram. Soc. 90 (2007) 870-877.

[40] C. Anandan, P. Bera, XPS studies on the interaction of $\mathrm{CeO}_{2}$ with silicon in magnetron sputtered $\mathrm{CeO}_{2}$ thin films on $\mathrm{Si}$ and Si3N4 substrates, Appl. Surf. Sci. 283 (2013) 297-303.

[41] P. Bera, C. Anandan, XRD and XPS studies of room temperature spontaneous interfacial reaction of $\mathrm{CeO}_{2}$ thin films on $\mathrm{Si}$ and $\mathrm{Si}_{3} \mathrm{~N}_{4}$ substrates, RSC Adv. 4 (2014) 62935-62939.

[42] L. Martínez, E. Román, J.L. de Segovia, S. Poupard, J. Creus, F. Pedraza, Surface study of cerium oxide based coatings obtained by cathodic electrodeposition on zinc, Appl. Surf. Sci. 257 (2011) 6202-6207.

[43] P. Scardi, R.D. Maggio, L. Lutterotti, P. Maistrelli, Thermal expansion anisotropy of ceria-stabilized tetragonal zirconia, J. Am. Ceram. Soc. 75 (1992) 2828-2832.

[44] C. Nandi, V. Grover, M. Sahu, K. Krishnan, A. Guleria, S. Kaity, A. Prakash, A.K. Tygai, $\mathrm{Nd}^{3+}$ - substituted $\left(\mathrm{Zr}_{1-\mathrm{x}} \mathrm{Ce}_{\mathrm{x}}\right) \mathrm{O}_{2}(0.0 \leq \mathrm{x} \leq 1.0)$ system: synthesis structure and thermophysical investigations, J. Nucl. Mater. 479 (2016) 152-161. 